\title{
Reducing Stigma of People with Disabilities: A Systematic Review
}

\author{
Eriando Rizky Septian 1 S (D) $\square$ and Ella Nurlaella Hadi² 8 (D), \\ ${ }^{12}$ Faculty of Public Health, University of Indonesia, Indonesia \\ $\square$ Corresponding Author: Eriando Rizky Septian, E-mail: eriando.rizky71@ui.ac.id
}

\section{ARTICLE INFORMATION}

Received: June 22, 2021

Accepted: August 02, 2021

Volume: 2

Issue: 2

Dol: 10.32996/jmhs.2021.2.2.3

\section{KEYWORDS}

Stigma, People with Disabilities, PubMed, ScienceDirect, ProQuest, Indonesia

\section{ABSTRACT}

People with Disability are having limited access to participation. The most significant barrier for people with disabilities to participate is stigma. However, there is a limited source of existing intervention to reduce stigma on people with disabilities. Indonesia, home of more than 20 million people with disabilities, is still having no effort in reducing stigma yet. Therefore, it is important to provide Indonesia with insight of interventions to reduce stigma on people with disabilities. The objective of the study was to provide insight of interventions to reduce stigma on people with disabilities around the world through a systematic review. The study employed $a$ systematic review following the methodological framework provided by Prisma multistep using electronic databases (PubMed, ScienceDirect, ProQuest), reference lists, and journals to locate studies. Inclusion criteria were based on title and content through keyword search with stigma, disability, and intervention as its keyword. The study revealed that from 449 articles that are found online, only 17 are eligible with the inclusion criteria. Most of the interventions are targeting to reduce stigma from the general population towards people with disabilities. Mental disability is the most type of disability addressed by the intervention. The study concluded that education intervention has proven to be the most effective and efficient type of intervention in reducing stigma toward people with disabilities. Especially in Indonesia, a fourth most populous country, increasing impact area by targeting the general population can be seen as the most efficient way in reducing stigma.

\section{Introduction}

Disability is not a mere problem. Globally, there are about $15 \%$ of the world's population with disabilities, among them, there are about 110-190 million people that are having significant difficulties in doing daily activities (Carroll, 2012). However, disability is still underdeveloped in most countries, as the result, people with disabilities have worse health and socio-economic condition than people without disabilities (Carroll, 2012; Clarke et al., 2015a). It can be seen by the lack of enablement support to people with disabilities through the provision of accessibilities. Lack of accessibilities for people with disabilities will become a barrier to improve people with disabilities quality of life (Vergunst et al., 2017). While it is hard to improve their quality of life, disability is highly related to poverty and often becomes a cause or consequence of disability (DFID, 2000).

To make the situation worse, people with disabilities still have to cope with stigmatizations, which then become another barrier for them to participate in the community (Lusli et al., 2016; Ruth M.H. Peters et al., 2015). Stigma is certain assumptions that people made that have an extensive discrediting effect (Goffman, 2005). Having years stigmatized as incapable and impaired, people with disabilities need a lot of support before they can improve their quality of life (Persons, 2012). For example, even though the government provides free health care for people with disabilities, it will not work if people with disability or their families are still ashamed of getting out of their house due to their enacted or perceived stigma about their disabilities. So, reducing stigmas are often the first step towards creating more accessible environments for persons with disabilities before they can improve their quality of life.

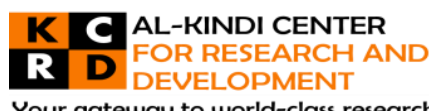

Your gateway to world-class research

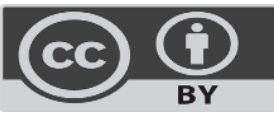

Published by Al-Kindi Center for Research and Development, United Kingdom. Copyright (c) the author(s). This open access article is distributed under a Creative Commons Attribution (CC-BY) 4.0 license 
In Indonesia, there are about $8.56 \%$ of people above two years old that is having a physical or sensory impairment (Statistik, 2015). To change it, Indonesia has made an effort by ratifying the United Nations Convention of Rights of People with Disabilities and has transformed it into Law of Disability No 8 years 2016. A set of policies is also applied to make sure that people with disabilities can access their rights. However, providing people with disabilities with accessible facilities and services is not enough. It is important to account knowledge and attitudes as important environmental factors that affect all areas of service provision and social life for people with disabilities (Bickenbach, 2011).

The problem is that there is no significant effort to reduce stigma on people with disabilities happening in Indonesia yet. Therefore, in order to give inputs to the government, this paper will try to search for an effective stigma reduction intervention that has been tested and published in the international journal by doing a systematic review. Through this systematic review, we would like to seek out how the stigma reduction effort has been done and how it is affecting people with disabilities. This way, the government could see the positive and negative aspects of each intervention and choose which one is suitable for Indonesia.

\section{Methodology}

The identification of studies evaluating the intervention in reducing the stigma of people with disabilities started with a search in bibliographical databases. Through several discussions with experts who have researched stigma reduction, "Stigma" is used as the main keyword that has to be present in their title, while "Disability" and "Intervention" are used as the main keyword that could be anywhere within the research articles. Medline, ScienceDirect, and ProQuest are chosen as the article sources, as they are rich in high-quality disability and health-related articles. The articles that are chosen have to be new in order to give us the updated type of intervention on stigma reduction, therefore the articles should be newer than 2008 (10 years) and duplicates were removed. Further selection was based on information through titles and abstracts and full text for some articles. Content analysis of words, phrases, or extracts accordingly to some pre-specified criteria was used, it has to describe stigma reduction intervention for people with disabilities.

In summary, the following inclusion criteria were established:

1. Focus on intervention to reduce stigma on people with disabilities;

2. Disability-related disease is included (such as leprosy, framboesia, etc.);

3. Publication dates from January 2008 to April 2018; and

4. Research articles from PubMed/Medline, ScienceDirect, and ProQuest that have been peer-reviewed.

Studies were excluded based on the following criteria:

1. Not doing any intervention that reduces stigma on people with disabilities;

2. Not directly related to a disability;

3. Published before 2008; and

4. Editorial, part of a book, review articles, or not empirical and peer-reviewed.

\section{Results}

From a total of 456 articles found online, 17 articles were identified for further review following the PRISMA multistep review process (Moher et al., 2009). The process is including reducing duplication and articles with limited access and analyzing the content to meet the criteria chosen. This process is visually described in Figure 1. Each article was reviewed and coded for (a) target population, (b) location, (c) method. The authors separately reviewed the articles and met several times throughout the process to compare and confirm findings. 
Figure 1. Systematic Prisma Article Identification Process.

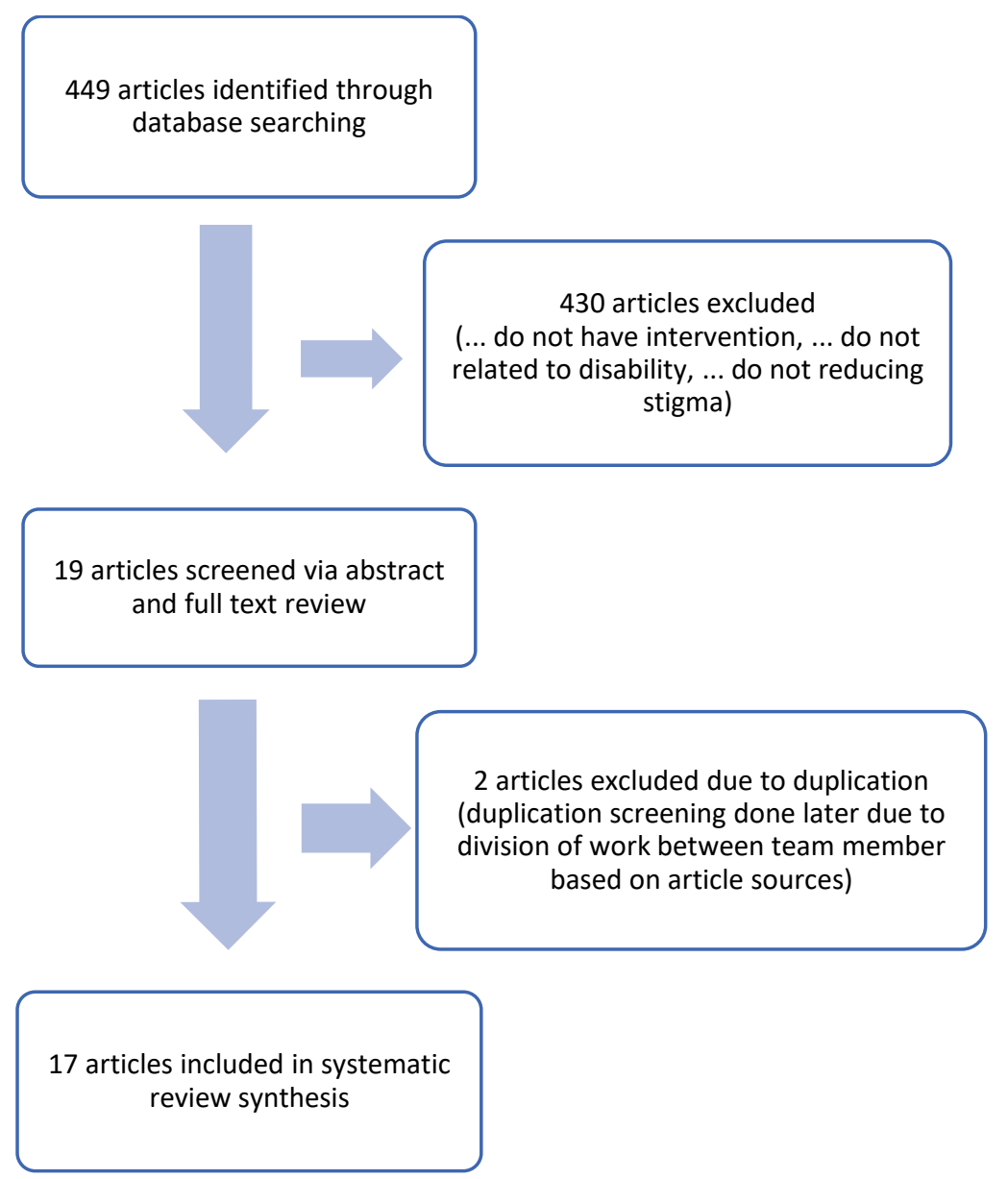

\subsection{Target Population}

Based on our findings, from the total of seventeen eligible articles, four articles are targeting people with disabilities (Chakraborty et al., 2014; Jung \& Kim, 2012; Lusli et al., 2016; R. M.H. Peters et al., 2016), while twelve articles are targeting general population around people with disability (Clarke et al., 2015b; Dharitri et al., 2015; Gillespie-Lynch et al., 2015; Hansson \& Markström, 2012; Mecarelli et al., 2015; Murman et al., 2014; R. M.H. Peters et al., 2016; Ruth M.H. Peters et al., 2015; Ranson \& Byrne, 2014; Spagnolo et al., 2008; Staniland \& Byrne, 2012; Tilahun et al., 2016; Walker \& Scior, 2013), and 1 article targeting both of people with disability and people with disability (Michaels et al., 2014). This finding indicated that in an effort to reduce stigma, most interventions are targeting the general population around people with a disability instead of focusing on reducing people with disability self-stigma because self-stigma is related to how their surroundings treat people with disabilities (Michaels et al., 2014; R. M.H. Peters et al., 2016; Ruth M.H. Peters et al., 2015).

From the four articles that are targeting people with disabilities, three of them are targeting people with a physical disability, while one of them are targeting people with mental disability. On the other hand, from twelve articles that are targeting the general population around people with disabilities, one of them is for reducing stigma towards people with physical disabilities (Ruth M.H. Peters et al., 2015), three of them are for reducing stigma towards people with intellectual disability (Gillespie-Lynch et al., 2015; Staniland \& Byrne, 2012; Walker \& Scior, 2013), and the rest, eight articles are for reducing stigma towards people with mental disability (Clarke et al., 2015b; Dharitri et al., 2015; Hansson \& Markström, 2012; Mecarelli et al., 2015; Murman et al., 2014; Ranson \& Byrne, 2014; Spagnolo et al., 2008; Tilahun et al., 2016). The last one is targeting both people with disabilities and the general population to reduce stigma on people with mental disabilities (Michaels et al., 2014). This finding implied that most of the interventions to reduce stigma for mental disability are targeting the general population instead of people with disabilities, especially when dealing with mental disability issues. The general population tends to look down on people with disabilities and treat them discriminative (Clarke et al., 2015b; Dharitri et al., 2015; Hansson \& Markström, 2012). On the contrary, to reduce stigma on people with physical disabilities, more interventions are targeting people with disabilities themselves. This is happening because 
some people with disability are having more self-stigma and need to be encouraged first before they can socialize with other (Lusli et al., 2016).

From the total of seventeen articles, mental disability is the main concern with a total of eleven articles trying to reduce its stigma (Chakraborty et al., 2014; Clarke et al., 2015b; Dharitri et al., 2015; Hansson \& Markström, 2012; Jung \& Kim, 2012; Mecarelli et al., 2015; Michaels et al., 2014; Murman et al., 2014; Ranson \& Byrne, 2014; Spagnolo et al., 2008; Tilahun et al., 2016). For intellectual disability, three articles addressing their writing to reduce the stigma on people with intellectual disability (Gillespie-Lynch et al., 2015; Staniland \& Byrne, 2012; Walker \& Scior, 2013), and three articles try to do intervention in reducing stigma on physical disability (Lusli et al., 2016; R. M.H. Peters et al., 2016; Ruth M.H. Peters et al., 2015). Most of the interventions are targeting to reduce the stigma on people with mental disabilities. It is because people with mental disabilities are prone to having low selfesteem and low quality of life while unable to actively defending themselves, which then will worsening their health condition (Chakraborty et al., 2014; Clarke et al., 2015b; Dharitri et al., 2015; Hansson \& Markström, 2012; Jung \& Kim, 2012; Michaels et al., 2014).

Figure 2. Target Population of Stigma Intervention

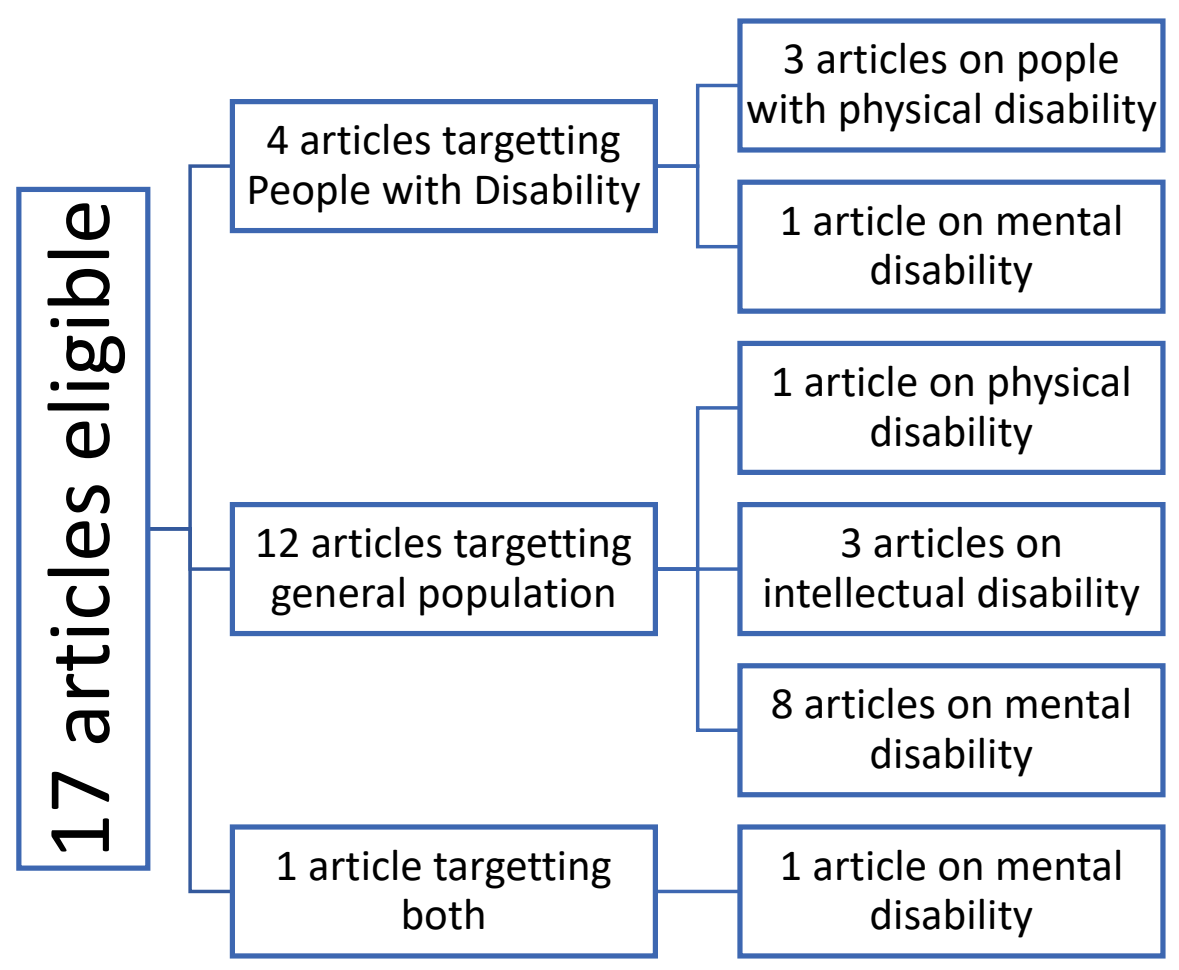

\subsection{Location}

From a total of 17 eligible articles, the USA is the country that has the most intervention done to reduce stigma towards disability with four articles (24\%). Indonesia is coming second with three articles (18\%) while the third position is a tie between Australia and UK with two articles (12\%). The rest are one article each for Ethiopia, India, Italy, Nigeria, South Korea. It is interesting to see how Indonesia, as a developing country, could take second place after the USA. After further reading, it appears that all the interventions that were done in Indonesia are related to leprosy and are done within the same settings in Cirebon, Indonesia. Interestingly, the intervention is divided into three interventions, which are counseling, contact, and video participatory.

\subsection{Participants}

There are 10.638 participants included in this review. The least number of participants is twelve people for an intervention targeting people with disabilities to reduce their self-stigma through the making of participatory video in Cirebon, Indonesia. The article with most participants is also from Cirebon, Indonesia with another intervention targeting the general population with contact intervention involving 4443 people. That makes the mean of participants within all eligible articles are 625,76 with a standard deviation of 1035,63 . The variety of participants here is relatively wide, it depends on who is the target of the intervention and how the intervention is used to reduce the stigma on people with disabilities. Most articles, especially with interventions targeting the general population, are using an education approach by giving the general population enough information to improve their 
knowledge and awareness about people with disabilities, therefore a large number of participants is needed. The variety of these articles with interventions targeting the general population is between 100-4443 people. On the other hand, with articles targeting people with disability to reduce their stigma is between $12-521$ people.

\section{Discussion}

To reduce stigma towards people with disabilities, many interventions can be used. Based on our findings, from seventeen eligible articles four are using contact interventions, while nine are using education interventions, two counseling interventions, one assessment intervention, and one both education and contact intervention. Counseling interventions are used in reducing stigma for people with disabilities while educational interventions are widely used in reducing stigma in the general population against people with disabilities. A significant attitude can be seen in the article "Working with Personality Disorders: Randomized Controlled Trials of Self-Management Versus Skills Training" while they use Commitment-based Therapy training interventions (ACTr) with dialectical knowledge and skills Behaviour Training interventions (DBTr) on staff working in state-funded or charitable services provide services to PD patients (Clarke et al., 2015b). As a result, ACTr respondents indicated that training influenced their personal thoughts and emotions to their patients, their urgent actions, and a sense of humanity with them. In contrast, DBTr respondents focused on impact training in their professional roles. The recommendations of this study try to maintain a loving care culture for staff working in charitable services or the like against patients with personality disorders.

In contrast to previous research on stigma interventions targeting other general populations in the journal "The effectiveness of an anti-stigma intervention in a basic police officer training program: a controlled study" using the method of anti-stigma intervention at a basic police officer training program (Hansson \& Markström, 2012). And the results of this anti-stigma intervention proved effective in changing attitudes, mental health literacy, and behavior in contacts between the police and persons with mental illness. Both journals demonstrated that important anti-stigma interventions were given to the general population who directly contacted patients with disabilities.

However, different training should not be given directly, in the journal "Student Concept Focus on Autism: Online Training to Improve Knowledge and Reduce Stigma" has conducted online training to college students (Gillespie-Lynch et al., 2015). This study aimed to increase knowledge and reduce the stigma associated with autistic students. The study also showed that online training could be a cost-effective way to increase students' understanding and acceptance of their colleagues with autism. This is of course very useful to increase the self-esteem and self-efficacy of people with autism in an educational environment.

Much literature reduces stigma focusing only on knowledge of improvement strategies to change behavior in the general population. In fact, it is not really enough to raise empathy, change fundamental attitudes, or reduce social distance with people with disabilities. The journal "Let's Erase the Stigma (LETS): Quasi-Experimental Evaluation of Youth School Groups Intended to Reduce Mental Stigma" suggests that discussion-oriented and action-oriented interventions may provide the new value of reducing stigma (Murman et al., 2014). LETS program provides a continuous dialogue in an interactive to discuss issues related to "difference" (including mental illness) and effect change strategies, with the overall aim of promoting de-stigmatization. Although this program is only applied to adolescents in schools it's possible if similar programs can be applied to a much wider community.

Moving on from education intervention that focuses on the improvement of knowledge, empathy, and changing fundamental attitudes, or reducing social distance on the general population, there is another type of intervention that has been used in reducing stigma, contact intervention. These interventions further emphasize the purpose of assessing the effect of the intervention on the stigma in the community. Five journals are using this method of which two are implemented in people with mental illness (MI), one physical disorder, and one intellectual disability. In all the journals there is only one study that intervenes to people with disabilities and the rest interventions made to the general population. It's specific to intervene in people with mental disabilities. A journal titled "The perceived stigma and quality of life of individuals diagnosed with schizophrenia and receiving psychiatric rehabilitation services: A comparison between the clubhouse model and the rehabilitation skills training model in South Korea" aimed to identify the perceived stigma and quality of life of individuals diagnosed with Schizophrenia at the rehabilitation center through the clubhouse model and skill training model. This study showed higher satisfaction in interpersonal relationships among the members of the clubhouse model in comparison with those participants of the rehabilitation skills training model. In the clubhouse, they feel not treated as patients, but as members. As a member, they objectively know about their mental illness, but despite having this disease, at least they can contribute to a reduction of their perceptions or experiences. And the result is contact intervention effectively able to increase knowledge and improve public attitude about leprosy. This method is also relatively easy to do somewhere and does not require expensive technology.

Educational and Contact Interventions are mostly applied to people with mental and developmental disabilities. While counseling interventions are applied to people with physical disabilities. In fact, this method is more applicable to people with disabilities than the general population. The journal "The Impact of a Rights-Based Counselling Intervention to Reduce Stigma in People Affected by Leprosy in Indonesia" used a rights-based approach, the Cognitive Behavioural Therapy (CBT) model, and three types of 
counseling. The unique feature of this intervention is that stigmatized individuals are trained and involved as lay and peer counselors. The findings demonstrate that the counseling intervention is effective in decreasing stigma, promoting the rights of people with leprosy, and facilitating their participation in family and community life. Consultation methods will become more effective when doing sustainably so that the design of costs becomes a consideration.

Other models found were assessment interventions. The journal "Stigma, explanatory models and needs of unaccompanied children's caregivers with developmental disorders in low-income African countries: cross-sectional facility-based surveys" examined the stigma experiences, preferred interventions, and coping mechanisms of caregivers of children with developmental disorders. The caregiver's experience becomes a form of assessment in describing the real condition of stigma in caring for a child with a developmental disability. This method seems to be an early stage before designing specific interventions. This means more research is needed to develop intervention assessments. The objectives of the intervention depend on the target group and the outcomes to be achieved. In the anti-stigma intervention in people with disabilities, it can be applied to sufferers, people around them, or even both.

\subsection{Study Limitations}

This systematic research was only including English and Open Access articles which may limit the scope of our findings that could lead to missing information. However, there are only 6 articles that fit into our inclusion criteria that do not have open access and 4 are written in the French language from our total of 449 reviewed articles. Moreover, excluding non-English articles has proven insignificant effect on systematic review and meta-analyses (Morrison et al., 2012).

\section{Conclusion}

Based on the systematic review done, there are some interventions available to reduce stigma on people with disabilities. However, from the process of finding eligible articles to suit our inclusion criteria, there are still limited articles that do an intervention to reduce stigma on people with disabilities. Most of them are still on the stage of assessing stigma on people with disabilities or doing intervention to reduce other stigma-related illnesses, such as HIV, TBC, etc. Dealing with Stigma, people with mental disability is often seen as the most stigmatized type of disability. Therefore, most articles found in this systematic review are trying to reduce stigma on people with mental disabilities. Education interventions have proven significantly successful in reducing the stigma by improving general population awareness and knowledge about people with mental disabilities. The same goes for developmental disability and physical disability as well.

For Indonesia, education intervention to reduce stigma on people with disabilities is recommended, due to its high impact and its do ability. Especially when dealing with a country with a lot of population such as Indonesia, widening the range of impact is only possible with education intervention which is relatively low easy to do compared to other types of intervention.

Conflict of Interest: The authors report no conflict of interest.

Funding: This study is self-funded.

\section{References}

[1] Bickenbach, J. (2011). The world report on disability. Disability and Society, 26(5), 655-658. https://doi.org/10.1080/09687599.2011.589198

[2] Carroll, A. (2012). World report on disability. Irish Medical Journal, 105(5), 1-2. https://doi.org/10.1111/j.1741-1130.2011.00320.x

[3] Chakraborty, A., Ghosh, S., Mukhopadhyay, P., Dinara, S. M., Bag, A., Mahata, M. K., Kumar, R., Das, S., Sanjay, J., Majumdar, S., \& Biswas, D. (2014). Trapping effect analysis of AlGaN/InGaN/GaN Heterostructure by conductance frequency measurement. MRS Proceedings, XXXIII(2), 81-87. https://doi.org/10.1007/s13398-014-0173-7.2

[4] Clarke, S., Taylor, G., Bolderston, H., Lancaster, J., \& Remington, B. (2015a). Ameliorating Patient Stigma Amongst Staff Working with Personality Disorder: Randomized Controlled Trial of Self-Management Versus Skills Training. Behavioral and Cognitive Psychotherapy, 43(6), 692-704. https://doi.org/10.1017/S1352465814000320

[5] Clarke, S., Taylor, G., Bolderston, H., Lancaster, J., \& Remington, B. (2015b). Ameliorating Patient Stigma Amongst Staff Working with Personality Disorder: Randomized Controlled Trial of Self-Management Versus Skills Training. Behavioral and Cognitive Psychotherapy, 43(6), 692-704. https://doi.org/10.1017/S1352465814000320

[6] DFID. (2000). Disability, Poverty, and Development. In World Hospitals \& Health Services (Vol. 38). https://doi.org/10.1332/policypress/9781847428851.001.0001

[7] Dharitri, R., Rao, S. N., \& Kalyanasundaram, S. (2015). Stigma of mental illness: An interventional study to reduce its impact in the community. Indian Journal of Psychiatry, 57(2), 165-173. https://doi.org/10.4103/0019-5545.158175

[8] Gillespie-Lynch, K., Brooks, P. J., Someki, F., Obeid, R., Shane-Simpson, C., Kapp, S. K., Daou, N., \& Smith, D. S. (2015). Changing College Students' Conceptions of Autism: An Online Training to Increase Knowledge and Decrease Stigma. Journal of Autism and Developmental Disorders, 45(8), 2553-2566. https://doi.org/10.1007/s10803-015-2422-9

[9] Goffman, E. (2005). Stigma and social identity. In Understanding Care, Welfare and Community: A Reader (First Touc, pp. 143-145). Simon \& Schuster Inc. https://doi.org/10.4324/9780203793343-4

[10] Hansson, L., \& Markström, U. (2012). Disability and poverty. In Disability and poverty (Vol. 14, Issue 1). https://doi.org/10.1332/policypress/9781847428851.001.0001 
[11] Jung, S. H., \& Kim, H. J. (2012). Perceived stigma and quality of life of individuals diagnosed with schizophrenia and receiving psychiatric rehabilitation services: a comparison between the clubhouse model and a rehabilitation skills training model in South Korea. Psychiatric Rehabilitation Journal, 35(6), 460-465. https://doi.org/10.1037/h0094580

[12] Lusli, M., Peters, R., van Brakel, W., Zweekhorst, M., lancu, S., Bunders, J., Irwanto, \& Regeer, B. (2016). The Impact of a Rights-Based Counselling Intervention to Reduce Stigma in People Affected by Leprosy in Indonesia. PLoS Neglected Tropical Diseases, 10(12), 1-26. https://doi.org/10.1371/journal.pntd.0005088

[13] Mecarelli, O., Messina, P., Capovilla, G., Michelucci, R., Romeo, A., Beghi, E., De Simone, R., Cerquiglini, A., Vecchi, M., Boniver, C., Monti, F., Ferlazzo, E., Gasparini, S., Baldassarri, C., Cesaroni, E., Stranci, G., Elia, M., Severi, S., Pizzanelli, C., ... Pruna, D. (2015). An educational campaign about epilepsy among Italian primary school teachers. 2. The results of a focused training program. Epilepsy and Behavior, 42, $93-97$. https://doi.org/10.1016/j.yebeh.2014.07.022

[14] Michaels, P. J., Corrigan, P. W., Buchholz, B., Brown, J., Arthur, T., Netter, C., \& Macdonald-Wilson, K. L. (2014). Changing stigma through a consumer-based stigma reduction program. Community Mental Health Journal, 50(4), 395-401. https://doi.org/10.1007/s10597-013-9628-0

[15] Moher, D., Liberati, A., Tetzlaff, J., Altman, D. G., Altman, D., Antes, G., Atkins, D., Barbour, V., Barrowman, N., Berlin, J. A., Clark, J., Clarke, M., Cook, D., D'Amico, R., Deeks, J. J., Devereaux, P. J., Dickersin, K., Egger, M., Ernst, E., ... Tugwell, P. (2009). Preferred reporting items for systematic reviews and meta-analyses: The PRISMA statement. In PLoS Medicine (Vol. 6, Issue 7). https://doi.org/10.1371/journal.pmed.1000097

[16] Morrison, A., Polisena, J., Husereau, D., Moulton, K., Clark, M., Fiander, M., Mierzwinski-Urban, M., Clifford, T., Hutton, B., \& Rabb, D. (2012). The effect of English-language restriction on systematic review-based meta-analyses: A systematic review of empirical studies. In International Journal of Technology Assessment in Health Care (Vol. 28, Issue 2, pp. 138-144). https://doi.org/10.1017/S0266462312000086

[17] Murman, N. M., Buckingham, K. C. E., Fontilea, P., Villanueva, R., Leventhal, B., \& Hinshaw, S. P. (2014). Let's Erase the Stigma (LETS): A QuasiExperimental Evaluation of Adolescent-Led School Groups Intended to Reduce Mental Illness Stigma. Child and Youth Care Forum, 43(5), 621-637. https://doi.org/10.1007/s10566-014-9257-y

[18] Persons, D. S. (2012). Disability and poverty. In Disability and poverty (Vol. 28, Issue 2). https://doi.org/10.1332/policypress/9781847428851.001.0001

[19] Peters, R. M.H., Zweekhorst, M. B. M., van Brakel, W. H., Bunders, J. F. G., \& Irwanto. (2016). 'People like me don't make things like that': Participatory video as a method for reducing leprosy-related stigma. Global Public Health, 11(5-6), 666-682. https://doi.org/10.1080/17441692.2016.1153122

[20] Peters, R. M.H., Dadun, Zweekhorst, M. B. M., Bunders, J. F. G., Irwanto, \& van Brakel, W. H. (2015). A Cluster-Randomized Controlled Intervention Study to Assess the Effect of a Contact Intervention in Reducing Leprosy-Related Stigma in Indonesia. PLoS Neglected Tropical Diseases, 9(10), 1-25. https://doi.org/10.1371/journal.pntd.0004003

[21] Ranson, N. J., \& Byrne, M. K. (2014). Promoting Peer Acceptance of Females with Higher-functioning Autism in a Mainstream Education Setting: A Replication and Extension of the Effects of an Autism Anti-Stigma Program. Journal of Autism and Developmental Disorders, 44(11), 2778-2796. https://doi.org/10.1007/s10803-014-2139-1

[22] Spagnolo, A. B., Murphy, A. A., \& Librera, L. A. (2008). Reducing stigma by meeting and learning from people with mental illness. Psychiatric Rehabilitation Journal, 31(3), 186-193. https://doi.org/10.2975/31.3.2008.186.193

[23] Staniland, J. J., \& Byrne, M. K. (2012). Disability and poverty. In Disability and poverty (Vol. 43, Issue 12). https://doi.org/10.1332/policypress/9781847428851.001.0001

[24] Statistik, B. P. I. (2015). Profil Penduduk Indonesia hasil SUPAS. In Journal of Petrology (Vol. 369, Issue 1). BPS. https://doi.org/2101033

[25] Tilahun, D., Hanlon, C., Fekadu, A., Tekola, B., Baheretibeb, Y., \& Hoekstra, R. A. (2016). Stigma, explanatory models and unmet needs of caregivers of children with developmental disorders in a low-income African country: A cross-sectional facility-based survey. BMC Health Services Research, 16(1), 1-12. https://doi.org/10.1186/s12913-016-1383-9

[26] Vergunst, R., Swartz, L., Hem, K. G., Eide, A. H., Mannan, H., MacLachlan, M., Mji, G., Braathen, S. H., \& Schneider, M. (2017). Access to health care for persons with disabilities in rural South Africa. BMC Health Services Research, 17(1), 741. https://doi.org/10.1186/s12913-017-2674-5

[27] Walker, J., \& Scior, K. (2013). Tackling stigma associated with intellectual disability among the general public: A study of two indirect contact interventions. Research in Developmental Disabilities, 34(7), 2200-2210. https://doi.org/10.1016/j.ridd.2013.03.024 